\title{
Vivência do preconceito racial e de classe na doença falciforme'
}

\section{Racial and class prejudice of experience in sickle cell disease}

\author{
Alessandra Varinia Matte Figueiró \\ Universidade Federal de Mato Grosso. Departamento de \\ Enfermagem. Programa de Pós-Graduação em Enfermagem. \\ Cuiabá, MT, Brasil. \\ E-mail: alessandra.matte77ðgmail.com

\section{Rosa Lúcia Rocha Ribeiro} \\ Universidade Federal de Mato Grosso. Departamento de \\ Enfermagem. Programa de Pós-Graduação em Enfermagem. \\ Cuiabá, MT, Brasil. \\ E-mail: rosaluciaðgmail.com
}

\section{Correspondência}

Alessandra Varinia Matte Figueiró

Rua São Joaquim, 588, Bairro Centro Sul.

Cuiabá, MT, Brasil. CEP 78020-150.

\section{Resumo}

Esse estudo, descritivo com abordagem qualitativa, tem por finalidade compreender as manifestações de discriminação racial e de classe que ocorrem com pessoas que vivenciam a doença falciforme. Participaram do estudo 33 pessoas. 0 corpus de análise foi composto do registro das narrativas e observações de campo contidas no Diário de Pesquisa. Os resultados mostraram que o preconceito na área da saúde, muitas vezes, se manifesta por meio do racismo institucional. No âmbito socioeconômico, as pessoas que vivenciam o agravo muitas vezes têm poder aquisitivo menor, em parte devido ao próprio racismo, e também devido às limitações que o adoecimento impõe. Evidenciamos que a qualidade de atendimento e infraestrutura dos serviços de saúde está diretamente relacionada à cor e classe social dos usuários. Com este estudo foi possível compreender mais profundamente esse fenômeno social em saúde, permitindo a elaboração de medidas para solucionar esse quadro de violação de direitos humanos. Assim, sugere-se a realização de outros estudos com foco nas implicações sociais da doença falciforme, para aprimorar a qualidade dos serviços de saúde prestados a essa população. Palavras-chave: Anemia Falciforme; Origem Étnica e Saúde; Preconceito; Classe Social; Cuidados de Enfermagem.

1 Pesquisa realizada com apoio da Coordenadoria de Aperfeiçoamento de Pessoal de Nível Superior (Capes) 


\section{Abstract}

This study aimed to understand the manifestations of racial and class discrimination that occur with people who experience sickle cell disease. Descriptive study with qualitative approach. The study included 33 people. The analysis corpus consisted of recording the narratives and field observations in the Research Diary. The results showed that the prejudice in health often manifests itself through institutional racism. In the socioeconomic sphere, people who experiencing the grievance often have lower income, partly due to racism itself, and also because of the limitations that illness impose. We showed that the quality of service and infrastructure of health services is directly related to color and social class of users. With this study, we more deeply understand this social phenomenon in health, allowing the development of measures to resolve this situation of violation of human rights. Thus, it is suggested to further studies focusing on the social implications of sickle cell disease, aiming to improve the quality of health services to this population.

Keywords: Anemia Sickle Cell; Ethnicity and Health; Social Class; Prejudice; Nursing Care.

\section{Introdução}

A doença falciforme define-se como uma hemoglobinopatia de origem genética que se caracteriza pela predominância da hemoglobina $\mathrm{S}(\mathrm{HbS})$ nas hemácias. Quando desoxigenada, esta sofre alterações em suas propriedades físico-químicas, que resultam na alteração da hemácia para o formato de "foice" (Brasil, 2015).

Diversos estudos de haplótipos sugerem que o gene determinante da HbS teve origem no ocidente centro-africano. A hipótese mais comum entre os geneticistas, para o desenvolvimento da doença falciforme, seria a de que se trata de um evento de seleção natural em seres humanos cuja forma heterozigótica oferece proteção parcial à malária (Brasil, 2015). Os estudos indicam que as migrações de populações ancestrais dispersaram o gene determinante da HbS por todo o continente africano, atingindo também algumas populações mediterrâneas. Além disso, surgiram outros haplótipos fora do continente africano, como na Arábia Saudita e na Ásia, os quais, provavelmente, tiveram origens distintas; no entanto, eles estão correlacionados com quadros clínicos menos graves, se comparados aos haplótipos africanos (Brasil, 2009b).

Na literatura, vários estudos sugerem que a origem da doença falciforme no Brasil ocorreu com a imigração forçada de povos africanos negros para serem escravizados no período de $155^{\circ}$ a $185^{\circ}$, estando hoje difundida por todo o mundo, atingindo predominantemente pessoas pretas e pardas, mas se encontra presente também em pessoas brancas (Brasil, 2009b).

É uma das alterações genéticas mais frequentes no Brasil que se distribui de forma heterogênea, apresentando maior prevalência onde a proporção da população negra é maior, cujas frequências do gene variam de $2 \%$ a $3 \%$ em todo o país, aumentando para 6\% a 10\% entre pretos e pardos (Brasil, 2015).

Isso representa um recorte, além de raça, também de classe para a doença, visto que a população negra, grupo étnico majoritariamente acometido, está na base da pirâmide social e apresenta os piores indicadores epidemiológicos, educacionais e econômicos (Brasil, 2006). 
Consideramos que os fatores socioeconômicos também contribuem significativamente para a variabilidade clínica e de prognóstico de pessoas com doença falciforme. As condições de moradia, a qualidade e quantidade insuficiente da alimentação ingerida e a carência de assistência à saúde, muitas vezes, estão associadas à discriminação racial, baixa renda e baixa escolaridade (Zago; Pinto, 2007).

A discriminação racial é aqui entendida como tratamento diferenciado em função da raça, colocando em desvantagem grupos raciais específicos. Significa qualquer distinção, exclusão, restrição ou preferência, baseados em raça, cor, descendência ou origem nacional ou étnica, que tenha por objeto ou efeito anular ou restringir o reconhecimento, o gozo ou o exercício em condições de igualdades fundamentais no domínio político, econômico, social e cultural ou em qualquer outro domínio na vida pública (Cordeiro; Ferreira, 2009).

Nos serviços de saúde podemos notar que a vulnerabilidade étnico-racial se manifesta pela discriminação racial ou pelo racismo institucional que:

Não se expressa em atos manifestos, explícitos ou declarados de discriminação. Ao contrário, (o racismo institucional) atua de forma difusa no funcionamento cotidiano de instituições e organizações, que operam de forma diferenciada na distribuição de serviços, benefícios e oportunidades aos diferentes segmentos da população do ponto de vista racial. Ele extrapola as relações interpessoais e instaura-se no cotidiano institucional, inclusive na implementação efetiva de políticas públicas, gerando, de forma ampla, desigualdades e iniquidades (Silva et al., 2009, p. 7).

As modalidades pelas quais essa discriminação se expressa, em sua maioria, não são diretas e evidentes, mas são envolvidas nas teias das relações sociais e econômicas que estruturam e determinam o processo saúde-doença, seja de seus determinantes diretos ou indiretos. É possível constatar que o acesso aos serviços de saúde varia para os diferentes grupos que compõem a população, com desvantagem para negros e pobres, e que os diferentes níveis de reprodução da desigualdade social e de saúde têm suas origens fortemente fincadas na raça e classe (Cordeiro; Ferreira, 2009).

Portanto, podemos considerar que as pessoas que vivenciam a doença falciforme se encontram em uma complexa situação de vulnerabilidade, que é definida por Ayres et al. (2009) como a exposição das pessoas ao adoecimento, como resultante de um conjunto de aspectos referentes ao indivíduo e sua relação com o coletivo. Esses aspectos não permeiam apenas as questões biológicas e do ambiente, mas também levam em consideração a cultura, questões socioeconômicas e sua história de vida, ampliando e valorizando, dessa forma, a subjetividade do indivíduo.

Desse modo, a doença falciforme pode ser considerada como uma situação crônica negligenciada, pois o diagnóstico muitas vezes é tardio, sendo comum, no cotidiano destas pessoas, atendimentos em serviços de emergência e frequentes internações que se constituem em momentos de desequilíbrio e de dificuldades. Além disso, o contexto dos serviços de saúde como espaço de manutenção e legitimação das desigualdades sociais e raciais permite que sejam criados mecanismos para práticas de discriminação racial por meio de atitudes negativas, como conversas depreciativas e tratamento injusto ou humilhante (Cordeiro; Ferreira, 2009).

O preconceito e a discriminação racial têm sido objeto de análise pelos cientistas sociais no Brasil, especialmente para pensar o impacto que estes fenômenos produzem na dinâmica das relações sociais e de desvendar e revelar a discriminação, racismo e outros processos que produzem a exclusão social. Com relação ao campo da saúde, os estudos são mais recentes e, sobretudo, mais difíceis de serem realizados, devido à dificuldade em evidenciar nas suas minúcias o intrincado campo das relações sociais entre usuários, profissionais de saúde e serviços de atendimento (Cordeiro; Ferreira, 2009).

Considerando todos esses elementos, surgiu o seguinte questionamento: o racismo na saúde estabelece repercussões no cotidiano de cuidado das pessoas que vivenciam a doença falciforme?

O estudo se justifica por evidenciar como ocorrem as situações de preconceito, tanto racial como de classe, no cotidiano de atendimento à saúde às pessoas que vivenciam a doença falciforme e por 
evidenciar, ainda, como as manifestações do preconceito se mostram sutis em nossa sociedade, de modo que as maiores vítimas são as pessoas pobres e de cor negra.

Assim, este estudo objetivou compreender as manifestações de discriminação racial e de classe que ocorrem com pessoas que vivenciam a doença falciforme.

\section{Metodologia}

Este artigo é um recorte da dissertação de mestrado intitulada “Terapia Comunitária Integrativa: cuidado as pessoas que vivenciam a Doença Falciforme". Essa dissertação se caracterizou como uma "pesquisa em interface com a intervenção", de modo que as pesquisadoras construíram uma forma de estudo utilizando princípios que unem a pesquisa com a intervenção.

Neste artigo, considerando o seu objetivo, os dados são apresentados de forma descritiva e analisados qualitativamente. Caracterizam-se como descritivos, pois o propósito geral foi apresentá-los de modo a revelar aspectos abrangentes e concernentes ao fenômeno recortado (Polit; Beck, 2011), e realizados de forma qualitativa, visto que buscaram a significação das relações, representações, crenças, percepções e opiniões humanas (Minayo, 2010); o que possibilitou a aproximação dos sentidos e significados da experiência de adoecimento das pessoas que vivenciam esse agravo.

Barreto (2008) define a Terapia Comunitária Integrativa (TCI) como um trabalho grupal, em que pessoas partilham experiências do cotidiano e saberes, de forma horizontal e circular, e utiliza uma dinâmica que possibilita às pessoas que dela participam a construção de redes de apoio.

O local designado para a realização do estudo foi um hemocentro público localizado na cidade de Cuiabá-MT. Este serviço é referência para o tratamento de pessoas com doença falciforme e outras hemoglobinopatias no estado de Mato Grosso e, por isso, pressupomos que o local facilitaria o maior acesso à população de interesse deste estudo.

Ficou instituído como critério de elegibilidade dos participantes que estes seriam pessoas e famílias/cuidadores que vivenciavam a doença falciforme, realizavam tratamento/acompanhamento no hemocentro público e que residiam no estado de Mato Grosso.

Totalizaram-se, então, 33 pessoas participantes do estudo, de modo que seis delas eram pessoas acometidas pela doença falciforme, dentre elas, quatro crianças; os outros 27 participantes eram familiares e/ou cuidadores. Das 27 pessoas adultas participantes, dezessete eram do sexo feminino e doze do sexo masculino. Das quatro crianças, duas eram do sexo masculino e duas do sexo feminino. Por fim, as duas pessoas idosas que participaram do estudo eram do sexo feminino. Quanto à raça/cor, considerando o nosso julgamento segundo as características fenotípicas, os 33 participantes foram assim classificados: seis pessoas de cor preta, catorze pessoas de cor parda e treze pessoas de cor branca.

A construção do material empírico se deu pela realização de seis rodas de TCI com pessoas que vivenciam a doença falciforme, de modo que todas foram realizadas em dias e horários pré-agendados, e o período de recolha dos dados ocorreu entre março e maio de 2015.

Na primeira roda de TCI participaram quatro pessoas e, nas quatro rodas seguintes, participaram duas pessoas em cada uma delas. A última roda de TCI teve um número mais expressivo de participantes, totalizando 23 pessoas. Houve uma mãe e seu filho que compareceram em duas das rodas. Com exceção deste caso, as demais rodas de TCI foram realizadas com grupos de pessoas diferentes.

Os registros das rodas de TCI e as observações realizadas foram gravados em áudio e vídeo e posteriormente foram transcritos. As narrativas e observações compuseram o corpus de análise desse estudo e foram registradas no Diário de Pesquisa (DP), conforme descrito por Araújo et al. (2013). 0 material foi organizado em arquivo de processador de texto Word for Windows 2007, na fonte Times New Roman em tamanho doze e espaçamento simples entre linhas, totalizando noventa páginas de texto.

Para avaliar os dados foi utilizada a análise temática, que consiste em descobrir os núcleos de sentido que compõem a comunicação, cuja presença e frequência signifiquem alguma coisa para o objeto 
analítico escolhido (Bardin, 1979). Na pesquisa qualitativa, a análise temática tem como eixo central o "tema", o qual comporta feixes de relações que podem ser apresentadas graficamente por uma palavra, frase ou resumo (Minayo, 2009).

A análise do material empírico se deu por meio de leituras exaustivas do DP, o que nos permitiu elencar dois conjuntos temáticos para discussão, que foram: a) o racismo e suas repercussões no cuidado à saúde de quem vivencia a doença falciforme; e b) as questões socioeconômicas e sua influência na qualidade dos serviços de saúde.

Em cumprimento às diretrizes e normas regulamentadoras de pesquisas envolvendo seres humanos, o estudo encontra-se em consonância com o projeto aprovado pelo Comitê de Ética em Pesquisa, sob protocolo no 921.261/CEP-HUJM/2014. A autorização dos participantes se deu por meio do Termo de Consentimento Livre e Esclarecido (TCLE) e a participação das crianças e adolescentes se deu por meio da assinatura do TCLE específico pelos pais das crianças/ adolescentes ou de seus responsáveis legais.

\section{Resultados e discussão}

\section{0 racismo e suas repercussões no cuidado à saúde de quem vivencia a doença falciforme}

Desde sua primeira descrição em 1910, a doença falciforme vem sendo associada a uma patologia prevalente em pessoas negras. No Brasil, considerando a intensa miscigenação racial, esta afirmação já não pode mais ser considerada como absoluta. Porém, ainda hoje a relação doença falciforme/população negra é muito forte, de modo que a categoria racial negra é considerada por muitos como um pré-requisito para ser acometido por este agravo, como podemos observar pelos seguintes relatos:

Então, quando eu disse assim, que eu descobri que eu tenho o pé na senzala, mas eu nunca diferenciei [...] Na verdade, quando eu fiz o meu curso [técnico em enfermagem] em 2002, a gente aprende: 'Ah é a doença do negro!' [enfático] [...] Mas eu não imaginava que a navalha ia cortar a minha carne (Amor - Pai).
Podemos notar, com este relato, que a associação dessa doença com as questões étnico-raciais é tão forte em nossa sociedade que também os cursos de formação na área da saúde a evidenciam com muita ênfase. No campo da saúde pública, a ênfase neste agravo como doença étnico-racial apoiou-se em três aspectos relacionados a essa patologia que caracterizariam uma maior suscetibilidade entre a população negra: origem geográfica, etiologia genética e as estatísticas de prevalência (Laguardia, 2006).

Conforme o estudo de Roberti et al. (2010), além da cronicidade da enfermidade, sobrevém uma íntima analogia da doença falciforme com a população negra, havendo um caráter estigmatizante decorrente da associação entre a clínica e a prevalência entre afrodescendentes. Essas seriam, portanto, pessoas marginalizadas socialmente e teriam perda significativa da qualidade de vida.

O relato de que a população negra está mais vulnerável a determinadas doenças é muitas vezes decorrente de práticas de racismo, sem que os profissionais considerem essa premissa. São com essas incongruências que se constituem e disseminam relações de poder com base em argumentos e concepções biologicistas, e é a partir desses contextos que se mantém o quadro de iniquidades raciais em saúde (Mendes; Costa; Ribeiro, 2015).

Neste sentido, podemos inferir que o descaso com as questões relativas à doença falciforme é, em grande parte, reflexo do preconceito racial existente na sociedade brasileira:

$\varepsilon$ É uma doença igual ta naquele cartaz ali [aponta para um cartaz informativo para denunciar casos de preconceito de cor no âmbito dos serviços de saúde], é o preconceito racial mesmo, porque vem de negro, vem de pobre, é uma doença muito mal informada. Porque se fosse uma doença que atingisse pessoas de cor mais clara, pessoas que têm nível social mais alto, eu tenho certeza que ela seria mais divulgada (Atitude - Mãe).

No relato podemos perceber que essa mãe relaciona diretamente a falta de informação sobre a doença falciforme ao racismo existente na sociedade, de modo que afirma que essa doença teria maior visibilidade no meio social se atingisse em 
maior número pessoas de cor branca e de poder aquisitivo elevado.

Consideramos, aqui, o racismo como um fenômeno ideológico, um importante fator de violação de direitos e de produção de iniquidades, especialmente no campo da saúde. 0 racismo tem relação com as condições em que a pessoa nasce, com sua trajetória familiar e individual, condições de vida, moradia, trabalho, emprego, renda e de acesso à informação e aos bens e serviços. O racismo também é visível na qualidade do cuidado e assistência prestada, nos perfis e estimativa de mortalidade infantil, nos sofrimentos evitáveis ou mortes precoces, nas taxas de mortalidade da população adulta e nos perfis epidemiológicos (Werneck, 2005).

Nesta perspectiva, o relatório publicado em setembro de 2014 pela Organização das Nações Unidas (UN, 2014), a partir da visita ao Brasil de um grupo de trabalho formado por três especialistas em dezembro de 2013, versa que o racismo no Brasil é estrutural e institucionalizado e "permeia todas as áreas da vida”, fato este que é evidenciado também pelos participantes:

Porque isso ta a nível Brasil, todo lugaré assim, aí é aonde o movimento negro chega dizendo que éo racismo institucional (Resiliência - Mãe).

Porque a população negra, queira ou não, tem inúmeros estudos mostrando que essa população tem o grupo que tem morrido mais, que tem sofrido as maiores privações em relação à saúde (Conhecimento - Docente da UFMT).

Neste sentido, o Programa de Combate ao Racismo Institucional (Silva et al., 2009, p. 22) implementado no Brasil em 2005 definiu o racismo institucional como:

O fracasso das instituições e organizações em prover um serviço profissional e adequado às pessoas em virtude de sua cor, cultura, origem racial ou étnica. Ele se manifesta em normas, práticas e comportamentos discriminatórios adotados no cotidiano do trabalho, os quais são resultantes do preconceito racial, uma atitude que combina estereótipos racistas, falta de atenção e ignorância.
Em qualquer caso, o racismo institucional sempre coloca pessoas de grupos raciais ou étnicos discriminados em situação de desvantagem no acesso a benefícios gerados pelo Estado e por demais instituições e Organizações (Silva et al., 2009, p. 22).

Imersos nessa perspectiva do preconceito, existe até um mito entre os profissionais de saúde, de que pessoas negras têm maior resistência à dor, visto que é comum os profissionais alegarem que a pessoa acometida por crise de dor na doença falciforme pode suportá-la sem analgesia adequada:

Muitos falam [profissionais de saúde]: "Ah... ela é negra, ela tem resistência! Ela aguenta!”[enfático] [...] O negro não tem dor, que se vire, que ele dê um jeito. “Ele aguenta!”[enfático] (Perseverança - Pai).

Isso faz com que os profissionais não forneçam a essas pessoas o tratamento analgésico adequado para sanar sua dor ou, em alguns casos, até mesmo não o fornecem. Essa situação deixa evidente que, em vários momentos, os profissionais de saúde estão tão imersos dentro da lógica do preconceito e segregação racial, que os mesmos são até capazes de cometer atos tão aquém de um ser humano, visto que o sofrimento físico e mental imposto pelo quadro de dor sem analgesia correta é muito intenso.

No estudo de Mendes, Costa e Ribeiro (2015), em que foi avaliado o racismo biológico e suas implicações no ensinar-cuidar a saúde da população negra, esse mito também se mostrou presente, de modo que uma profissional enfermeira e docente afirmou que existem diferenças raciais biológicas que determinam a maior resistência à dor e longevidade de uma criança negra que vivencia a doença falciforme em detrimento a uma criança branca.

Neste sentido, Leal, Gama e Cunha (2005) analisaram as desigualdades sociais referentes ao acesso e utilização dos serviços de saúde em relação à cor da pele em amostra representativa de puérperas que demandaram atenção hospitalar ao parto, e também evidenciou-se que:

nos serviços de saúde as mulheres também se diferenciaram segundo o grau de instrução e cor da pele. No pré-natal houve menor acesso a atenção 
adequada em acordo aos padrões estabelecidos pelo Ministério da Saúde. No momento do parto, foram mais penalizadas por não serem aceitas na primeira maternidade que procuraram e, durante o parto, receberam menos anestesia. Essas diferenças no tratamento oferecido foram apreendidas pelas mulheres ao avaliarem a qualidade dos serviços oferecidos a elas. Novamente, o mesmo padrão se estabelece na relação com os serviços de saúde, por instrução e por cor da pele (Leal; Gama; Cunha, 2005, p. 106).

Por diversas vezes, a dor é tão intensa que só é possível cessá-la com um analgésico opioide, geralmente a morfina. Mas, por ser este um fármaco que tem como efeito colateral o risco para dependência física, os profissionais de saúde, tomando por base ideias desprovidas de fundamentação científica e preconceituosas, costumam desacreditar da dor da pessoa adoecida e, no caso de pessoas negras, estes as desqualificam duplamente, relacionando um possível vício em medicamentos à sua cor:

Quando chegam os meninos negros, grandes, com dor, ai já falam [profissionais de saúde] que é viciado: 'Ah o viciadinho, lá vem o viciadinho da morfina!' [enfática] (Resiliência - Mãe).

Pressupomos que isso ocorra devido ao mito que existe na sociedade de que pessoas negras fazem maior uso de substâncias químicas. Essa afirmação é incoerente visto que a cor da pele em nada tem relação com a predisposição ao uso de entorpecentes. Consideramos que as condições socioeconômicas precárias, sim, é que têm potencial para influenciar nesse processo. A existência desse tipo de relação pejorativa existente na sociedade só deixa mais evidente o quão o racismo é presente e forte em nosso cotidiano.

O estudo de Cordeiro e Ferreira (2009) em que foi tratada a discriminação racial e de gênero em discursos de mulheres negras com doença falciforme, demonstrou que os espaços onde mais ocorreram situações de preconceito foram as unidades de emergência hospitalares, já que é por este caminho que mais rapidamente as pessoas são atendidas quando acometidas por crises dolorosas.

Nesses locais, a discriminação se traduz pela falta de orientação médica sobre a doença e o tratamento e, muitas vezes, por receberem medicamentos e cuidados que não são adequados ao diagnóstico. Relatam também o mau humor das enfermeiras, pois estas afirmam que as mulheres negras são viciadas em medicamentos (Cordeiro; Ferreira, 2009).

A lógica de depreciar e invalidar o sujeito leva ao sentimento de desvalorização e diminuição. A instituição de saúde participa desse processo de exclusão e o torna inaudível: grande parte do que se fala não é levado a sério ou acreditado como verdade, há um silencio geral, o que pode ser denominado como a "lógica da invisibilidade do sofrimento" (Batista; Silva, 2007).

Estereótipos étnicos ou raciais pejorativos, incapacidade em responder à diversidade, julgamentos negativos e atitudes racistas são fatores que comprometem a comunicação efetiva entre paciente e profissional de saúde e, consequentemente, a satisfação, adesão, confiança, utilização dos serviços e o resultado final da ação em saúde. A baixa qualidade do cuidado, a informação inadequada, a insensibilidade às preocupações, interesses e perspectivas individuais contribuem, desse modo, para a manutenção e ampliação das iniquidades étnico-raciais no cuidado em saúde (Laguardia, 2006).

Podemos verificar, então, que os serviços de saúde, por meio de seus profissionais, aumentam a vulnerabilidade da população negra, ampliando barreiras ao acesso, diminuindo a possibilidade de diálogo e provocando o afastamento de usuários. No caso específico da doença falciforme, patologia genética de maior prevalência entre essa população, a sua invisibilidade nos serviços de saúde, a ausência de informação sobre o tema nos aparelhos formadores (universidades), a falta de informação/formação específica para os profissionais e a inexistência de programas de atenção às pessoas que vivenciam a doença é a expressão material do racismo institucional (Kalckmann et al., 2007).

Considerando este contexto, na tentativa de assegurar os direitos destas pessoas, em 16 de agosto de 2005, foi publicada a Portaria de $\mathrm{n}^{0} 1.391$, que institui, no âmbito do SUS, as diretrizes para a Política Nacional de Atenção Integral às Pessoas com Doença Falciforme e outras Hemoglobinopatias (Brasil, 2005). 
Posteriormente, na tentativa de enfrentar o racismo na saúde, foi criada pelo Ministério da Saúde, em maio de 2009, a Política Nacional de Saúde Integral da População Negra (PNSIPN), reconhecendo as desigualdades raciais como fatores que interferem no processo saúde, doença, cuidado e morte, bem como a necessidade de implementar políticas para combater as iniquidades (Brasil, 2009a).

Fica evidente pelos relatos a percepção deste pai que afirma que, mesmo com a criação de políticas públicas de saúde destinadas a esta população, a saúde das pessoas negras não teve melhora suficiente em sua qualidade:

A saúde tem leis, mas não avança, não melhora! [...] Quando a gente fala que tem que olhar pra saúde da população negra, que tem até uma lei, mas nesse sentido muitos não acreditam porque não conhecem (Perseverança - Pai).

O relato acima evidencia que as leis e políticas que amparam a população negra existem, mas que, mesmo assim, a situação de saúde desse segmento continua precária, demonstrando que as políticas existentes que envolvem a saúde dessa população não estão sendo de fato implementadas pelo poder público.

Pressupomos que essa situação derive do fato de que o racismo seja um dos principais elementos estruturantes da nossa sociedade, tão importante quanto a questão de classe. Como já está amplamente demonstrado em estudos, o racismo reflete-se nos diversos âmbitos da vida social, desde os restritos investimentos em políticas públicas dirigidas à população negra e pobre, mas especialmente no âmbito das subjetividades e das relações.

Como exemplo temos a grande resistência das instituições de ensino, de todos os níveis, em adaptarem seus currículos às Diretrizes Curriculares Nacionais para a Educação das Relações Étnico-Raciais e para o Ensino de História e Cultura Afro-Brasileira e Africana, instituída pela Resolução do Conselho Nacional de Educação $n^{0}$ 1/2004 (CNE, 2004), derivada da Lei 10.639/2003 (Brasil, 2003). Na educação superior, em nosso meio, essa resistência se agrava ainda mais com a constante negação do racismo, conforme demonstrou o estudo de Mendes, Costa e Ribeiro (2015).
Do mesmo modo tem ocorrido na área da saúde, com a resistência à implementação da PNSIPN, demonstrado pelo desconhecimento das instituições formadoras (universidades) e até de gestores da saúde. Essa constatação nos foi possível durante o desenvolvimento dessa pesquisa, no contato com docentes da universidade e com gestores da área da saúde locais.

Para sensibilizar a sociedade da precariedade dos serviços de saúde a essas pessoas e também do preconceito que essas sofrem em seu cotidiano, é necessário o investimento de recursos para o desenvolvimento de ações educativas, tanto para os usuários dos serviços como também para os profissionais e gestores de saúde.

Para Mallmann et al. (2015, p. 7):

As intervenções educativas podem ser abordadas de diversas maneiras, entre as quais se destacam as atividades grupais, que podem promover a interação social e auxiliar na melhoria da qualidade de vida, o que dependerá dos meios utilizados para conduzir tais atividades, da abordagem dos assuntos e das necessidades dos participantes. Para melhoria dos domínios físico, psicológico e social, bem como a autonomia da pessoa que vivencia a doença falciforme, os quais impactam diretamente a qualidade de vida, o enfermeiro pode promover ações educativas grupais, a fim de estreitar o vínculo com a pessoa adoecida, identificar os fatores que interferem na sua autonomia e desenvolver ações em conjunto.

Nesse contexto, a TCI pode atuar como uma ação educativa em potencial para as pessoas que vivenciam a doença falciforme e também pode ser um modo de cuidado interessante a ser proporcionado pelos enfermeiros a essas pessoas, visto que a TCI:

Proporciona uma mudança de atitude quando cria um espaço de diálogo que não existia na vida de seus participantes, um mundo comum de argumentação sobremaneira particular e também oferece oportunidades para que as pessoas façam parte de um espaço público, e esse mecanismo demonstra que elas são dotadas de direitos, ao vivenciarem manifestações de aprendizado e inclusão social que são comuns a todos os participantes das rodas. 
Assim esse modo de cuidado pode auxiliar na condução de mudanças na vida de seus participantes a partir do desenvolvimento do ser político e da busca da cidadania (Giffoni, 2008, p. 07).

\section{As condições socioeconômicas e seu impacto na qualidade do atendimento a saúde}

Ampliando ainda mais esta vertente, o estudo evidenciou que o preconceito racial foi percebido pelos participantes como existente em nossa sociedade e que influencia de maneira negativa o âmbito das condições socioeconômicas dessas pessoas:

As pessoas com anemia falciforme são, geralmente, financeiramente menos favorecidas porque eles são descendentes de negros, aí o pessoal tem um poder aquisitivo menor [...] Eu acho que é preconceito com certeza, a anemia falciforme é a mesma coisa [...] (Amor - Pai).

[...] os negros, o pobre, o miserável, a grande maioria fica sofrendo nesse processo [...] Tudo no Brasil avança, menos para o povo negro que é a maioria, tem pobre também que é penalizado nesse sentido. Porque é 'preconceito e discriminação!' [enfático] (Perseverança - Pai).

Nesse sentido, a maior parte das pessoas que vivenciam a doença falciforme sofre duplamente, pois, além de sofrerem preconceito por serem de cor negra, também sofrem preconceito por serem economicamente menos favorecidas.

É sabido que pessoas negras têm menores oportunidades de acesso à educação, a entrada e a ascensão no mercado de trabalho, entre outros, e que, por isso, muitas vezes vivem em locais onde a insalubridade é muito grande. A ONU reafirmou no documento divulgado no mês de setembro de 2014 que os negros são os que têm menor escolaridade e salários, maior taxa de desemprego, menor acesso à saúde e menor participação no Produto Interno Bruto (PIB) (UN, 2014).

Podemos observar que, além da influência negativa do preconceito racial, os participantes percebem a existência de reverberações socioeconômicas que a própria doença impõe:
Emprego, eles [pessoas acometidas] não conseguem, porque começam a trabalhar e aí é 3 ou 4 dias por mês faltando, porque tem que consultar, fazer exames, quando dá a crise de dor ai o patrão fala: "tchau...não dá..." (Perseverança - Pai).

A pessoa que vivencia esse agravo tem muita dificuldade para manter-se estável em um vínculo empregatício, visto que é necessário se ausentar em muitos momentos do seu local de trabalho para realizar exames, consultas médicas, internações, entre outros, o que acaba por desencorajar os empregadores a contratar ou manter no emprego pessoas que vivenciam a doença falciforme.

Corroborando com essa afirmação, Silva, Ramalho e Cassorla (1993) versam que no âmbito profissional a doença assume caráter preocupante, uma vez que as constantes crises de dor, internações hospitalares e consultas médicas interferem no momento da aquisição de um emprego e, consequentemente, impõe uma situação financeira precária.

Além de não conseguirem emprego, as pessoas que tem seus relatos expostos a seguir denunciam que os portadores da doença falciforme não são juridicamente amparados por motivo de doença:

[...] em lei não está reconhecido que a anemia falciforme pode ter um amparo social ou mesmo aposentar, não tem, não está regulamentado (Perseverança - Pai).

Não temos nenhum amparo, o doente falciforme não tem nem aposentadoria, ele tem que ter outro adoecimento para ser aposentado [aposentadoria por doença incapacitante] (Respeito - Pai).

Essa situação evidencia que, além de essas pessoas não conseguirem manter-se em um vínculo empregatício, ao mesmo tempo, essas não são amparadas pelo serviço da Previdência Social, de modo que não têm um subsídio financeiro nos casos em que a doença as impede de trabalhar, o que inviabiliza sua subsistência. Isso é preocupante, uma vez que compromete sobremaneira suas condições de ter uma vida digna.

No âmbito do atendimento à saúde, pudemos evidenciar que a prestação de serviços em uma instituição de iniciativa privada tem melhor qualidade, visto 
que, em sua maioria, atende pessoas de maior poder aquisitivo. Já o atendimento dos serviços públicos se apresenta com qualidade inferior, já que atende pessoas mais pobres. Esta relação entre a situação financeira e a qualidade do atendimento à saúde esteve muito presente nos relatos dos participantes:

'Infelizmente médico vê que quanto mais pobre é, mais pisa! Mais quer ficar pendurado no SUS e menos quer trabalhar, essa é que é a verdade!' [enfático] Todo médico são dois: um que atende o pobre e outro que atende quem tem dinheiro. 'Muda completamente!' [enfático] (Perseverança-Pai).

\section{[...] Quando você chega no atendimento particular} [serviço de saúde particular] é totalmente diferente do que quando você vai lá no P. A. [serviço de s aúde público], é outro atendimento [...] (Amor - Pai).

Aqui podemos notar que as próprias pessoas que convivem com esse doença percebem a diferença dos serviços prestados a pessoas de maior poder aquisitivo, em detrimento de pessoas de origem mais humilde, diferença esta que muitas vezes se traduz pela discrepância na qualidade tanto estrutural como também do atendimento dos profissionais de saúde.

Essa ideia corrobora com o estudo de Nunes et al. (2014) em que afirmam que as condições socioeconômicas na doença falciforme influenciam sobremaneira na qualidade do atendimento à saúde. Nesse estudo verificaram-se desigualdades socioeconômicas no acesso e na qualidade da atenção prestada aos indivíduos mais pobres e menos escolarizados, e que essa constatação serve de alerta para as diferenças conceituais e operacionais entre uso e acesso aos serviços de saúde.

A diferença que existe na qualidade dos serviços de saúde público e privado, muitas vezes, faz com que essas pessoas tenham vontade de procurar por outros serviços de melhor qualidade, geralmente na iniciativa privada:

Não tem como, não tem saída porque a família não tem recursos pra você dizer assim: "Ah... leva pra um lugar mais desenvolvido". Condições não têm... ai você vai no médico e vê no que vai dar, não tem outra solução (Sabedoria - Pessoa adoecida).
Porém, o que podemos perceber é que essas pessoas são impedidas de fazê-lo porque não têm condições financeiras, visto que a maior parte dos serviços de saúde de qualidade é da iniciativa privada. Isso faz com que as pessoas que vivenciam esse adoecimento fiquem a mercê de serviços públicos de saúde sucateados e, além disso, são submetidas a situações de preconceito que podem comprometer ainda mais o seu estado de saúde.

Visto todos estes elementos, inferimos que as questões étnico-raciais e socioeconômicas interferem significativamente na qualidade e no acesso aos serviços de saúde prestados às pessoas que vivenciam a doença falciforme, de modo que o racismo institucional ainda é muito presente no contexto desses serviços.

Dessa maneira, os relatos dos participantes possibilitaram uma melhor compreensão desse fenômeno, fazendo-nos refletir sobre a importância de serem implementadas de fato as políticas de saúde específicas para esta população, pois ficou evidente que estes necessitam imediatamente de uma assistência à saúde voltada para suas reais necessidades.

\section{Considerações finais}

A população negra, historicamente, vem sendo penalizada em diversos contextos sociais devido ao estigma do qual são vítimas: o preconceito racial. Ainda hoje podemos perceber este preconceito como algo muito evidente na sociedade brasileira, atingindo diretamente o contexto de vida das pessoas que vivenciam a doença falciforme, visto que este agravo atinge em sua maioria pessoas de cor parda e preta.

Devido ao preconceito, pessoas negras têm menores oportunidades de acesso à educação e a uma boa colocação no mercado de trabalho, ocasionando, consequentemente, que elas tenham uma situação socioeconômica mais desfavorável. Outro fator que agrava este quadro é a própria doença falciforme, de modo que impõe muitas limitações à pessoa adoecida na tentativa de manter seu vínculo empregatício.

Pudemos evidenciar que tal situação de vulnerabilidade social interfere diretamente na qualidade do serviço de saúde prestado às pessoas acometidas por este agravo, de maneira que estas sofrem diariamente com situações de preconceito racial, violações de direitos e humilhações que muitas vezes são veladas. 
Essas pessoas têm que lidar, ainda, com o preconceito relacionado à sua situação socioeconômica, já que pudemos observar que os serviços de saúde oferecidos à parcela mais pobre da população têm uma qualidade inferior quando comparados aos serviços de saúde oferecidos às pessoas com poder aquisitivo mais alto.

Nesse cenário, o estudo foi de suma importância, pois ajudou a evidenciar com mais detalhes como ocorrem situações de preconceito envolvendo as questões étnico-raciais e socioeconômicas na doença falciforme e, assim, possibilitou o melhor entendimento deste fenômeno social em saúde, o que pode ser um incentivo para que os gestores e também profissionais de saúde passem a tomar medidas mais enérgicas na tentativa de solucionar esse quadro tão grave de violação de direitos humanos.

No âmbito desta temática ainda há muitas questões a serem exploradas. Nesse sentido, sugerimos a realização de mais estudos que abordem a vertente das implicações sociais na doença falciforme, com vistas a aprimorar a qualidade dos serviços de saúde prestados a essa população.

\section{Referências}

ARAÚJO, L. F. S. et al. Diário de pesquisa e suas potencialidades em pesquisa qualitativa. Revista Brasileira de Pesquisa em Saúde, Vitória, v. 15, n. 3, p. 53-61, 2013.

AYRES, J. R. C. M. et al. O conceito de vulnerabilidade e as práticas de saúde: novas perspectivas e desafios. In: CZERESNIA, D.; FREITAS, C. M. (Org.). Promoção da saúde: conceitos, reflexões, tendências. 2. ed. Rio de Janeiro: Fiocruz, 2009. p. 121-144.

BARDIN, L. Análise de conteúdo. Lisboa: Edições 70, 1979.

BARRETO, A. P. Terapia comunitária passo a passo. Fortaleza: Gráfica LCR, 2008.

BATISTA, C. B.; SILVA, L. R. Sentimentos de mulheres soropositivas para HIV diante da impossibilidade de amamentar. Escola Anna Nery Revista de Enfermagem, Rio de Janeiro, v. 11, n. 2, p. 268-275, 2007.

BRASIL. Lei n ${ }^{0} 10.639$, de 9 de janeiro de 2003. Altera a Lei no 9.394, de 20 de dezembro de 1996, que estabelece as diretrizes e bases da educação nacional, para incluir no currículo oficial da Rede de Ensino a obrigatoriedade da temática "História e Cultura Afro-Brasileira”, e dá outras providências. Diário Oficial [da] República Federativa do Brasil, Brasília, DF, 10 jan. 2003. Disponível em: <http:// bit.ly/1JeRoNF>. Acesso em: 10 fev. 2016.

BRASIL. Portaria MS nº 1.391/GM de 16 de Agosto de 2005. Institui no âmbito do Sistema Único de Saúde as diretrizes para a Política Nacional de Atenção Integral às Pessoas com Doença Falciforme e outras Hemoglobinopatias. Diário Oficial [da] República Federativa do Brasil, Brasília, DF, 16 ago. 2005. Disponível em: <http:// bit.ly/2j7Q9ap>. Acesso em: 10 fev. 2016.

BRASIL. Ministério da Saúde. Saúde Brasil 20o6: uma análise da situação de saúde no Brasil. Ministério da Saúde, Brasília, DF, 20o6. Disponível em: <http://bit.ly/2jE7aIk>. Acesso em: 13 jan. 2017.

BRASIL. Ministério da Saúde. Portaria MS $\mathrm{n}^{0}$ 992, de 13 de maio de 2009. Institui a Política Nacional de Saúde Integral da População Negra. Diário Oficial [da] República Federativa do Brasil, Brasília, DF, 2009a. Seção 1. Disponível em: <http://bit.ly/2jrcsIo>. Acesso em: 10 fev. 2016.

BRASIL. Ministério da Saúde. Manual de educação em saúde: Volume 2: linha de cuidado em doença falciforme. Brasília, DF: Ministério da Saúde, 2oogb. Disponível em: <http://bit. ly/2iPgWro>. Acesso em: 13 jan. 2017.

BRASIL. Ministério da Saúde. Doença falciforme: conhecer para cuidar. Brasília, DF: Ministério da Saúde, 2015. Disponível em: <http://bit. ly/2jM8gpN>. Acesso em: 25 nov. 2015.

CNE - CONSELHO NACIONAL DE EDUCAÇÃO. Diretrizes Curriculares Nacionais para a Educação das Relações Étnico-Raciais e para o Ensino de História e Cultura Afro-Brasileira e Africana. Brasília, DF: Conselho Nacional de Educação, 2004. Disponível em: <http://bit. ly/2daykZc>. Acesso em: 10 fev. 2016.

CORDEIRO, F. C.; FERREIRA, S. L. Discriminação racial e de gênero em discursos de mulheres negras com anemia falciforme. Escola Anna Nery 
Revista de Enfermagem, Rio de Janeiro, v. 13, n. 2, p. 352-358, 2009.

GIFFONI, F. A. O. Saber ser, saber fazer: terapia comunitária, uma experiência de aprendizagem e construção da autonomia. 2008. Tese (Doutorado em Educação) - Universidade Federal do Ceará, Fortaleza, 2008.

KALCKMANN, S. et al. Racismo institucional: um desafio para a equidade no SUS? Saúde e Sociedade, São Paulo, v. 16, n. 2, p.146-155, 2007.

LAGUARDIA, J. No fio da navalha: anemia falciforme, raça e as implicações no cuidado à saúde. Revista Estudos Feministas, Florianópolis, v. 14, n. 1, p. 243-262, 2006.

LEAL, M. C.; GAMA, S. G. N.; CUNHA, C. B. Desigualdades raciais, sociodemográficas e na assistência ao pré-natal e ao parto, 1999-2001. Revista de Saúde Pública, São Paulo, v. 39, n. 1, p. 100-107, 2005.

MALLMANN, D. G. et al. Educação em saúde como principal alternativa para promover a saúde do idoso. Ciência e Saúde Coletiva, Rio de Janeiro, v. 20, n. 6, p. 1763-1772, 2015.

MENDES, V. S.; COSTA, C. S.; RIBEIRO, R. L. R. Racismo biológico e suas implicações no ensinar-cuidar a saúde da população negra. Revista da ABPN, Florianópolis, v. 7, n. 16, p. 190-213, 2015 .

MINAYO, M. C. S. Pesquisa social: teoria, método e criatividade. Petrópolis: Vozes, 2009.

MINAYO, M. C. S. O desafio do conhecimento: pesquisa qualitativa em saúde. São Paulo: Hucitec, 2010.

NUNES, B. P. et al. Desigualdades socioeconômicas no acesso e qualidade da atenção nos serviços de saúde. Revista de Saúde Pública, São Paulo, v. 48, n. 6, p. 968-976, 2014.

UN - UNITED NATIONS. Report of the Working Group of Experts on People of African Descent on its fourteenth session. 2014. Disponivel em: <https://goo.gl/BqIbXu>. Acesso em: 9 set. 2015.

POLIT, D. F.; BECK, C. T. Fundamentos de pesquisa em enfermagem: avaliação de evidências para a prática de enfermagem. 7. ed. Porto Alegre: Artmed, 2011.

ROBERTI, M. R. F. et al. Avaliação da qualidade de vida em portadores de doença falciforme do Hospital das Clínicas de Goiás, Brasil. Revista Brasileira de Hematologia e Hemoterapia, São Paulo, v. 32, n. 6, p. 449-454, 2010.

SILVA, R. B. P.; RAMALHO, A. S.; CASSORLA, R. M. S. A anemia falciforme como problema de Saúde Pública no Brasil. Revista de Saúde Pública, São Paulo, v. 27, n. 1, p. 54-58, 1993.

SILVA, J. et al. A promoção a igualdade racial em 2006 e o Programa de Combate ao Racismo Institucional. In: JACCOUD, L. (Org.). A construção de uma política de promoção da igualdade racial: uma análise dos últimos vinte anos. Brasília, DF: Ipea, 2009. p. 7-170.

WERNECK, J. Iniquidades raciais em saúde e políticas de enfrentamento: as experiências do Canadá, Estados Unidos, África do Sul e Reino Unido. In: BRASIL. Fundação Nacional de Saúde. Saúde da população negra no Brasil: contribuições para a promoção da equidade. Brasília, DF: Funasa, 2005. p. 315-386.

ZAGO, M. A.; PINTO, A. C. S. Fisiopatologia das doenças falciformes: da mutação genética à insuficiência de múltiplos órgãos. Revista Brasileira de Hematologia e Hemoterapia, São Paulo, v. 29, n. 3, p. 207-214, 2007.

\section{Contribuição das autoras}

Figueiró foi responsável pela concepção do estudo e análise dos dados. Ribeiro contribuiu substancialmente no planejamento e na revisão crítica do conteúdo, e participou da aprovação da versão final do artigo. Ambas as autoras contribuíram para a redação do artigo.

Recebido: 08/03/2016

Aprovado: $28 / 11 / 2016$ 